\title{
EXCISION OF THE ENTIRE SCAPULA.
}

\author{
By A. B. MITCHELL, M.B., F.R.C.S.I.;
}

Surgeon, Royal Victoria Hospital, Belfast.

[Read in the Section of Surgexy, February 23, 1906.]

Excision of the entire scapula is a comparatively rare operation. It would appear to have been first suggested by Liston in 1819, but the proposal met with much hostile criticism - the general opinion expressed by surgeons of his day being, that it would involve great risk of life, whereas, even if successful, the best that could be hoped for would be a flail-like, useless arm. It was not till 1855, thirty-six years after Liston's original proposal, that Langenbeck successfully performed the first complete operation. His patient was a boy of twelve years, who, however, died three and a half months later of recurrence of the sarcomatous growth, on account of which operation had been undertaken.

The practicability of the operation had, however, been demonstrated during the intervening years, and many details of the operative technique had been gradually elaborated. 1 Thus in 1824 Jansen, of Lyons, removed the entire body of the scapula; in 1830 Skey, of London, removed all but the glenoid process ; in 1849 Lentin remored all but part of the acromion; in 1850 Langenbeck remored all but the coracoid, and in 1853 Brüns all but the acromion and coracoid. The only record of a complete excision carried out in Ireland which I have been able to find is by F. Alcock-Nixon, who successfully removed the entire bone for sarcoma in Mercer's Hospital, Dublin, the case being reported in the British Medical Journal, 1881, Vol. II., p. 1056. 
In 1874 , and again in 1875 , the scapula was removed in Mercer's Hospital for necrosis, and the entire bone is said to have been excised with excellent functional results in both eases. In July, 1895, Dr. Darling, of Lurgan, removed all but the acromion, coracoid and glenoid processes. The patient was shown at the meeting of the North of Ireland Branch of the British Medical Association in October, 1895, the result being a very useful arm. The movements and contour of the shoulder joint were almost perfect. The tumour for which operation was undertaken proved to be a chondroma. This patient, Dr. Darling informs me, is still living, and in excellent health ten years after operation. The chief dangers associated with the operation are :-

(1) Sepsis.

(2) Hæmorrhage.

Modern surgical technique has so greatly diminished both these risks that Schultz, taking only cases recorded since 1875 , estimates the mortality at $r$ per cent.; and it is interesting to note that the mortality of the complete operation is distinctly less than that of partial operation.2

Excision of the scapula is, therefore, a thoroughly justifiable operation from the point of view of actual risk. It remains to be considered whether it is also justifiable from the standpoint of the utility of the limb which is left. When we reflect that this procedure involves complete separation of the attachments of the levator anguli scapulæ, rhomboids, serratus magnus, teres major and minor, supra- and infra- spinatus, pectoralis minor, coraco-brachialis, both heads of the biceps, long head of triceps and, finally, a portion of the deltoid and trapezius-there would certainly appear to be ample justification for the fears expressed by Liston's contemporaries. It is, however, truly remarkable what a useful limb actually remains 
after such extensive mutilation, and it is chiefly in illustration of this fact that I bring forward my case as a contribution to the literature of the subject.

Mr. W., aged forty-five, who had always enjoyed good health, and had no family history bearing on the present affection, came to me on 14th July, 1905. He stated that about five years previously he had first noticed a slight pain over the right triceps muscle. He paid little attention to this, and it almost disappeared. In 1902, three years before I saw him, whilst throwing a stone, he suddenly felt " a sort of catch" in his right shoulder. Since then his arm had been weak; his shoulder had got gradually stiffer, and its range of movement more circumscribed. He suffered from a sensation of tingling down the forearm, and pains, sometimes severe, radiated into his hand. He had next a fairly constant aching pain about the shoulder, and latterly this pain had been much worse at night, and frequently wakened him out of sleep. When I saw him he required to support the right forearm; he could not raise the arm to a right angle with the trunk, and there was slight wasting of the muscles, apparently from disuse. Examination of the shoulder revealed a swelling, about the size of an egg, between the spine of the scapula behind and the clavicle in front. This swelling was slightly lobulated, firm and circumscribed, but not uniform in consistence, one spot about the size of a shilling being distinctly elastic. The tumour moved with the scapula. It did not involve the skin. I regarded it as a slowly-growing sarcoma of the scapula. A radiogram seemed to confirm this view. Professor Sinclair saw him with me. Although there was absolutely no specific history, we decided to put him on iodide of potash, and to submit him to a course of X-rays under the care of Dr. Rankin. He derived no benefit from the iodide, but the $\mathrm{X}$-ray treatment promptly relieved the pain and enabled him to sleep comfortably. The rays, however, gave rise to a dermatitis and had to be suspended, when the pain at once returned. As there had been no diminution in the size of the tumour, I advised him to have the scapula excised. He had occasion to go to London on business, and whilst there consulted Mr. Bland-Sutton, who also urged immediate operation. 
We delayed a week in the hope that the X-ray dermatitis would subside, but as improvement was very slow, operation was carried out in presence of the eruption. It is interesting here to note that this eruption did not in any way interfere with the healing of the wound, which united primarily except at the points of drainage. On 25th Sept., 1905, in a nursing home, he was anæsthetised by Dr. Fielden, and I had the benefit of Professor Sinclair's assistance and advice.

Lines of attack on the scapula vary according to the surgeon. The favourite incisions appear to be $(a)$ a transverse incision following the line of the spine of the scapula and extending from just outside the tip of the acromion to the vertebral border, supplemented by a vertical incision from the centre of the spine fo below the inferior angle. (b) Picqué ${ }^{3}$ employs the same horizontal incision with a second along the axillary border of the scapula, curving at the upper end around the acromion process as far as may be necessary to secure satisfactory exposure of the suprascapular regions and vessels. (c) Watson Cheyne commences with an incision along the anterior border of the axilli, secures and ligatures the sub-scapular artery, which is the commonest source of dangerous hæmorrhage, separates the short head of the biceps, coraco-brachialis and pectoralis minor and the coracoid process, then turns the patient round and completes the operation from behind.

The advantages of this method appear to me to be outweighed by the practical impossibility of keeping both the anterior and posterior wounds aseptic. In the huge cavity left after the removal of the scapula and its surrounding muscles the danger of sepsis is the greatest of all dangers, and for this reason I decided against a line of attack which has many attractions. Hæmorrhage-if we exclude secondary hæmorrhage following sepsis-can be certainly controlled by the careful application of ligatures before 
the vessels are divided, and should not, I think, be a serious eause for anxiety.

In this instance I decided to make my second incision along the vertebral border of the scapula so as to provide easy access to the posterior scapular artery and enable the attachment of the levator anguli scapulæ to be divided without difficulty. The skin incisions having been made, the deltoid and trapezius were rapidly detached from the acromion and spine of the scapula, and the acromio-clavicular point opened, and when this was done a mass of yellowish gelatinous material was found in the infraspinatous fossa, extending for about one and a half inches below the spine. Regarding this as sarcomatous we decided to freely remove the neighbouring portion of the trapezius. The latissimus dorsi was next dislocated off the inferior angle of the bone; the posterior scapular artery defined and ligatured at the superior angle, after which the rhomboid, levator anguli scapulæ, and serratus magnus were rapidly detached from the posterior border by aid of scissors. Attention was next directed to the axillary border. The subscapular artery, the most fertile source of hæmorrhage, was secured and ligatured without difficulty-- the scapula being rotated so as to bring the long head of the triceps into view; this was next divided. The supra- and infra- spinatus were divided close to the attachment to the humerus, and the shoulder joint opened. At this stage, unfortunately, the cirumflex nerve was cut, and I would like to emphasise the danger of wounding this nerve. With forcible rotation and dragging on the partially freed scapula it is apt to be somewhat displaced and to lie further out from the neck of the humerus than would be expected. The cut ends were united by catgut sutures. The capsule of the joint was divided close to its attachment to the humerus, and at the same time the tendons of the long head of the biceps and subscapularis were severed. It only remained to secure the supra-scapular artery and divide the insertion of the coracho-brachialis, biceps, and pectoralis minor, which was effected without difficulty. Oozing, which was slight, having been arrested, the scapular attachment of the serratus magnus was fixed by a few catgut stitches to the fascia over the erector spinæ. The deltoid was carefully sutured to the periosteum, 
covering the posterior border of the clavicle so as to support as far as possible the head of the humerus and prevent that tendency to drop away from the clavicle which other operators have described, and which is calculated to interfere materially with the subsequent usefulness of the limb. The radiogram which I exhibit, taken three months after operation, shows that the head of the humerus remains in excellent position close up to the clavicle. Very free drainage having been provided, the wounds were covered with the usual sterilised dressings, the arm bandaged to the side, with the elbow well supported. The operation occupied one hour and forty minutes; shock was fairly severe, but in no sense alarming. The total loss of blood only amounted to a few ounces. Subsequent recovery was very satisfactory. He had slight suppuration along the track of the drainage tubes, otherwise union was primary. He left the hospital in five weeks, at which time he was able to write letters with his right hand. His condition has steadily continued to improve. For almost three months he was unable to dresí himself, as he could not get the right arm into the sleeve of his shirt or coat, and was, therefore, unable to go from home overnight. He has now overcome this difficulty, and can put on all his clothes, including a heavy overcoat, without assistance. Examination of the arm and shoulder gives the impression of an unreduced dislocation of the humerus. There is only very slight power of abduction, but, by aid of the pectoralis major and latissimus dorsi, both of which muscles were left intact, the arm can be carried a short distance forwards and backwards around the thorax. Notwithstanding the fact that both heads of the biceps and the long head of the triceps have no longer any bony attachment, he has excellent power of flexion and extension at the elbow. The functions of forearm and hand are perfect in all respects. He has a large amount of correspondence, and he informs me that he can write without difficulty and without the slightest fatigue. Sensation is practically normal over the shoulder and arm. There is no indication of any trophic lesion. The tumour when cut into showed numerous soft hæmorrhagic areas. Professor Symmers reports it to be an enchondroma with areas of hæmorrhage, and in the neighbourhood of the capsule round-celled inflammatory infiltration, but without any evidence 
of malignancy. There is, therefore, every reason to expect a permanent cure. The usefulness of the arm is most satisfactory. When we consider that no mechanical appliance can be obtained, which in the very slightest degree compensates for the loss of the fingers and thumb with their wonderful combination of movements, it is evident that complete excision of the scapula is eminently justifiable, whether viewed in regard to the subsequent functional power of the limb or to the mortality of the operation itself, which, under modern technique, should probably not exceed 5 per cent.

This operation receives very scant attention in most of the text-books on surgery and operative surgery, but the literature of the subject is now fairly extensive. The most exhaustive article $I$ have had access to is that by Picqué et Dartigues, in the Revue de Chirurgie, Tome XXI., 1900, p, $437-438$.

' Sydney Delaup. Annals of Surgery. October, 1902. P. 523.

2 Picqué and Dartigues. Revue de Chirurge. Tome XXI. 1900. P. 437, 438.

${ }^{3}$ Revue de Chirurgie. Tome XXI. 1900. P. 437. 